\title{
Nutritional Factors and Three Most Prevalent Types of Osteoarthritis Arthritis - A Short Review
}

\author{
Jai S Ghosh* \\ Department of Biotechnology, India
}

Received: 制May 28, 2018; Published: 制June 05, 2018

*Corresponding author: Jai S Ghosh, Department of Biotechnology, Smt KW College, Assistant Professor, Sangli 416416, India

\begin{abstract}
One of the most common diseases of bone is arthritis. This disease affects the movable joints like that of knee, knuckles and some time hip joint. The three types of arthritis that are usually observed are osteoarthritis, rheumatoid osteoarthritis and gout related osteoarthritis. Basically in all these types of osteoarthritis, vitamin $\mathrm{K}$ related diet intake is recommended as this vitamin activates the GLa proteins by $\gamma$ carboxylation resulting in proper mineralization of bones and cartilages. In case of Gout related arthritis, purine rich food should be avoided along with alcoholic drinks like beer.
\end{abstract}

Keywords: Arthritis; Osteoarthritis; Cartilage; Gout; Vitamin K

\section{Introduction}

The word arthritis indicates pain in joints in the body. It is because in the joints the two bones are separated by a soft tissue which mostly cartilaginous in nature. Its only when this soft tissue is degenerated then the two ossified bones rubs against each other to generate pains. This is the simplest form of explanation for arthritis [1]. Therefore, one can note that the disease is a degenerative disease. There are different reasons for such a degeneration of the soft tissue. One of the most common reason when the degeneration occurs in the hip joints or in the knee joints is because of overweight of the body which is borne on these two types of joints for a long time leading to gradual degeneration of the soft tissue at these joints. Some time due excessive physical work like lifting of heavy loads can also result in degeneration over a period. Ultimately the last but not the least reason is that the degeneration is due to an autoimmune condition when the immune system of the body destroys this soft tissue in the joints. This condition is called as rheumatoid arthritis [2]. The other two reasons stated prior to this leads to what is known as osteoarthritis. The third arthritis that one often sees is due to deposition of uric acid crystals in the joints leading to inflammation of the joints and this is the gout related arthritis [3]. The suffering (mostly the excruciating pain) is further aggravated by psychological conditions in many elderly people when patients are living an isolated solitary life with nobody nearby [4].

\section{Preventive Nutritional Factors}

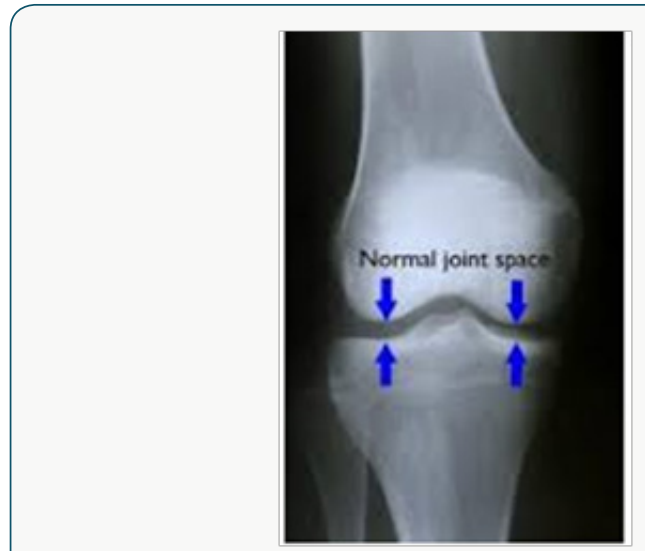

Figure 1: Normal knee joint.

Whatever may be the reason, the most important question often asked is: can this degeneration be prevented or ameliorated by nutritional factors? If one sees the literature available on prevention of such a condition [5], then one would see that two important vitamins should be provided through nutrition and these are viz. vitamin D and more important is vitamin K or phylloquinone, which is responsible for $\gamma$ carboxylation of Gla proteins like Matrix Gla proteins (MGP proteins) , osteocalcin, Gas 6 etc. The active form of these proteins (produced in presence of vitamin $\mathrm{K}$ ) is responsible for bone and cartilage mineralization in joints [5]. The inactive 
forms have no functions at all. If these do not take place properly then osteoarthritis symptoms are seen (especially in knee joints). Figure 1 shows a X-ray image of normal knee joint and Figure 2 shows X-ray image of a osteoarthritic knee joint.

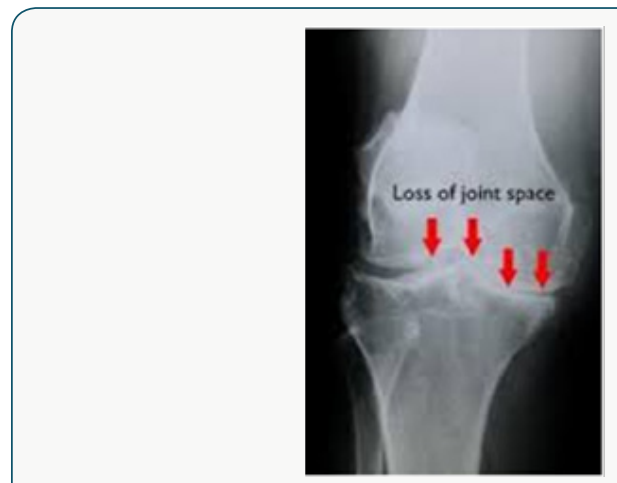

Figure 2: Arthritis at knee joint.

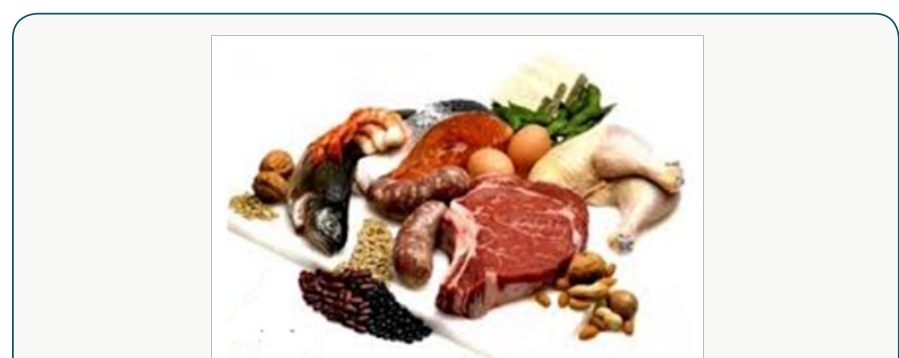

Figure 3: Foods to be avoided by gout patients.

Vitamin $\mathrm{K}$ rich foods are leafy vegetables like spinach, cauliflower, cabbage etc. These nutritional advice also ameliorate rheumatoid arthritis also to some extent but should be combined with other chemotherapeutic treatment. In case of gout (previously referred to as king's disease) related arthritis, is due to consumption of food that causes slow-down of removal of uric acid [6]. These include foods which are rich in purines and drinking too much alcohol especially beer. The other factors are overweight, diabetes, taking certain diuretics. This uric acid will then get deposited in crystalline form in the joints causing pains like osteoarthritis as movability of these joints gets highly restricted. The patients are advised under such condition is to avoid highly proteinaceous food like meat, eggs etc. like along with drinks like beer. Figure 3 shows foods that must be avoided by patients suffering from gout and Figure 4 shows the foods that should be taken (of course keeping other health related conditions in mind) by patients of gout.

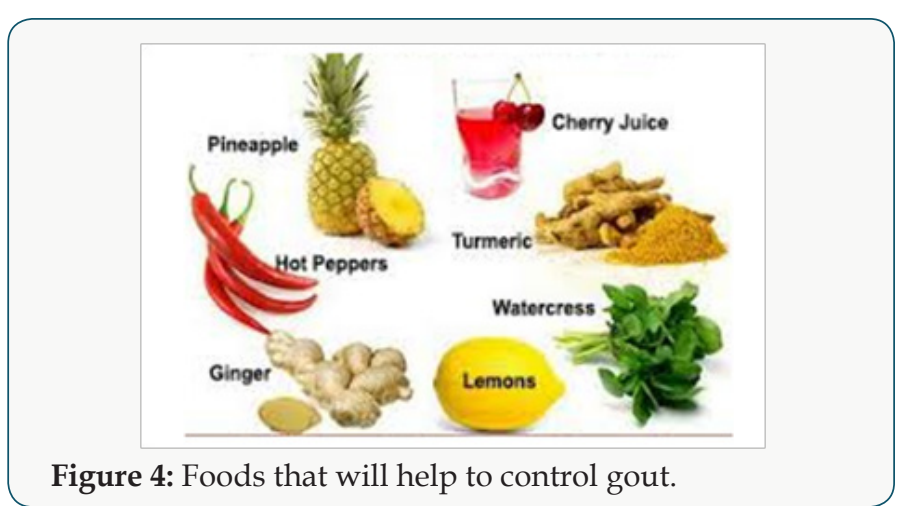

\section{References}

1. Athanasiou KA, Darling EM, Hu JC, DuRaine GD, Reddi AH (2013) Articular Cartilage. CRC Press pp. 439.

2. Chan KW, Felson DT, Yood RA, Walker AM (1994) The lag time between onset of symptoms and diagnosis of rheumatoid arthritis. Arthritis and Rheumatism 37(6): 814-820.

3. Becker MA (2005) Arthritis and Allied Conditions: A textbook of Rheumatology Lippincott Williams \& Wilkins pp. 2100.

4. March L, Smith EU, Hoy DG, Cross MJ, Sanchez Riera L, et al. (2014) Burden of disability due to musculoskeletal (MSK) disorders. Best practice and research. Clinical rheumatology 28(3): 353-366.

5. Devyani M, Sarah L, Booth IT, David TF, Michael CN, et al. (2013) Vitamin K Deficiency Is Associated with Incident Knee Osteoarthritis. American Journal of Medicine 126(3): 243-248.

6. Beyl RN, Hughes L, Morgan S (2016) Update on Importance of Diet in Gout. The American Journal of Medicine. 129(11): 1153-1158.

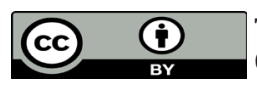

This work is licensed under Creative Commons Attribution 4.0 License

To Submit Your Article Click Here: Submit Article

DOI: $10.32474 /$ SJFN.2018.01.000110

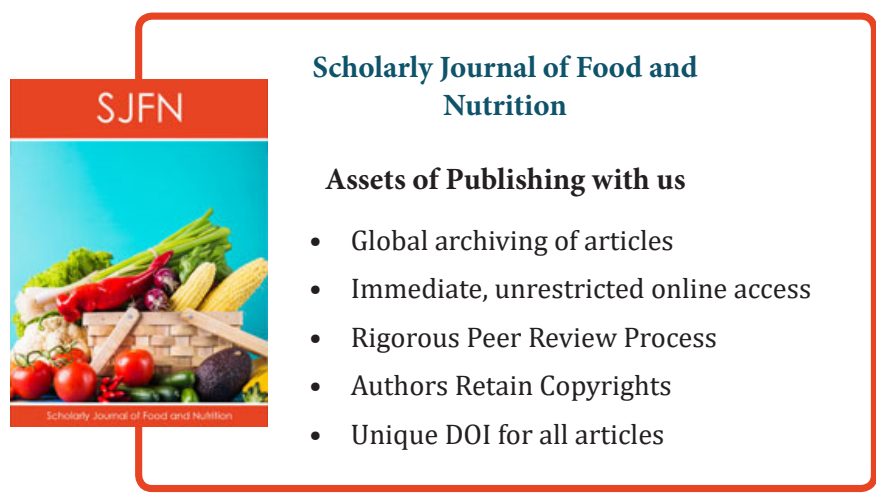

